Article

\title{
Experiment Investigate on the Effectiveness of Flexible Pipes to Isolate Sea-Water Pump Generated Vibration
}

\author{
Yang Yang ${ }^{1,2, *}$, Guang Pan ${ }^{1}$, Shaoping Yin ${ }^{2}$ and Ying Yuan ${ }^{3}$ \\ 1 School of Marine Science and Technology, Northwestern Polytechnical University, Xi'an 710072, China; \\ panguang601@163.com \\ 2 The 705 Research Institute, China Shipbuilding Industry Corporation, Xi'an 710077, China; \\ summertalentyy@163.com \\ 3 School of Physics and Optoelectronic Engineering, XIDIAN University, Xi'an 710071, China; \\ yuanying1989@126.com \\ * Correspondence: allen-yang1988@mail.nwpu.edu.cn
}

Received: 5 November 2019; Accepted: 31 December 2019; Published: 3 January 2020

\begin{abstract}
Vibration control is important in maintaining the silence of the underwater vehicle. Among the many methods of vibration control, isolation is by far the most efficient approach. However, as one of the major vibration sources in underwater vehicle, the vibration isolation of the sea-water pump has not been well explored. The sea-water pipe is the primary vibration transmit path from the sea-water pump to the housing. In order to realize the vibration isolation of the sea-water pump, the sea-water pipe must have certain flexibility and damping. In this study, scaled model tests were carried out to investigate the isolation effectiveness of flexible pipes in isolated sea-water pump. Specifically, three types of flexible pipes, i.e., double layer metal bellows (DLMB), rubber pipes $(\mathrm{RP})$ and bellows coated rubber (BCR) were designed and tested. Tests were carried out under the operation rotate speeds of the sea-water pump. Our results show that compared with single layer metal bellows (SLMB), the isolation effectiveness of DLMB and BCR were significant and stable in high frequency regions. The optimal pipe can be chosen for different vibration reduction requirements in practical engineering.
\end{abstract}

Keywords: underwater vehicle; sea-water pump; vibration isolation; flexible pipes

\section{Introduction}

Thermodynamic underwater vehicle power system includes the main engine and multiple auxiliary engines. As shown in Figure 1, the power plant is integrated and supported to the housing through front and rear vibration isolators. The basic function of the vibration isolators is to support the entire power plant, which are called "supporting devices". In addition to vibration isolators, there are also some pipes connected auxiliary engines to the housing, such as sea-water pipes, fuel pipes and oil pipes. The main function of these pipes is to complete the transportation of seawater, fuel and oil, without support functions, collectively referred to as "un supporting devices". The mechanical vibration of power plant during operation transmit to the housing through these supporting and unsupporting devices, and then generate radiated noise in the ocean. The sea-water pump is one of the major vibration and noise sources in the underwater vehicle power system. There are two basic directions to decrease the impact of the sea-water pump generated vibration for the whole vehicle in practical engineering, the first is reducing the vibration of the pump itself, e.g., reduce rotting speed and the optimized structural form. The second is decreasing the vibration transmission in the transfer path. Compared with reducing the vibration of the pump, which needs to sacrifice pump power and 
increase development cost, the same effectiveness can be achieved from the transfer path without affecting the performance of the product.

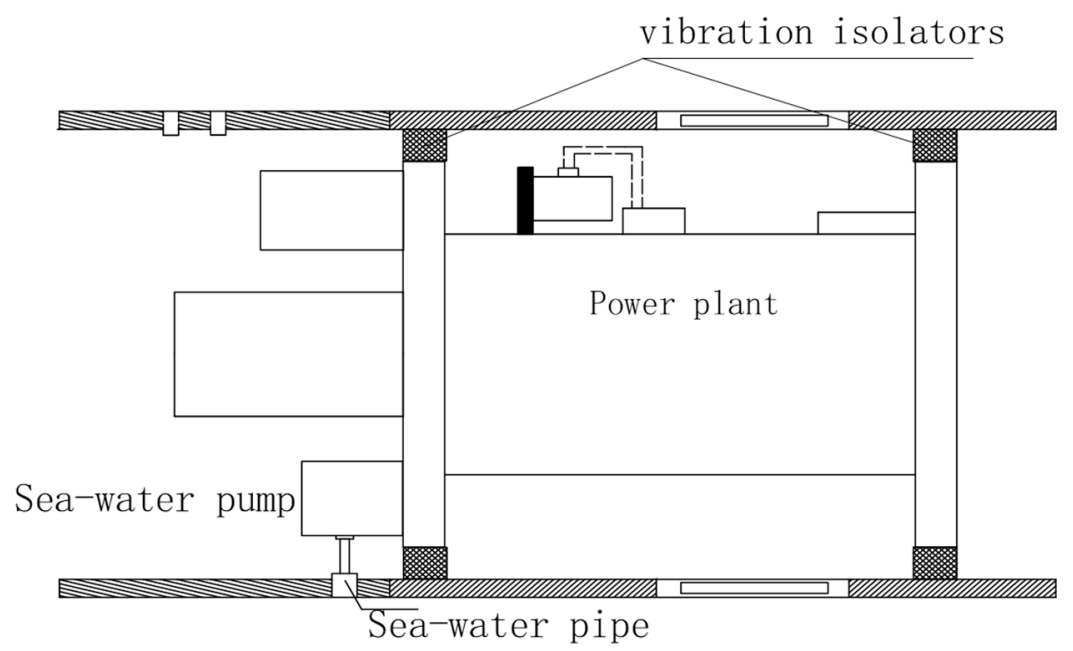

Figure 1. The position of the sea-water pipe in the power system.

The sea-water pipe as the exclusive path to transport the seawater from ocean to the vehicle is the primary path to transmit the mechanical and fluid-excited vibration of sea-water pump to housing during operation. Therefore, the vibration reduction design of the sea-water pipe is of great importance for the silence of underwater vehicle. Single layer metal bellows (SLMB) are widespread applied for its easy processing and long life in practical engineering. However, the pipe could not offer significant and stable vibration reduction for its large stiffness and small damping. In order to reduce fluid induced pulsation, a muffler usually be utilized inside a SLMB. However, the presence of the muffler has an effect on the flow of water in the pipe. As a result, under technically feasible conditions, engineers first consider the flexible connection without a muffler between the sea-water pump and the housing. Due to its good vibration isolation and impact resistance, the flexible pipe can effectively isolate the transmission of mechanical vibration energy of the power equipment to the housing. Besides the function of vibration reduction, the advantage of flexible pipes also includes the role of displacement compensation to avoid a great displacement induced by the equipment force. As the primary transfer path from the sea-water pump to the housing, the design of flexible pipe is much more significant for the vibration reduction of the housing. Nevertheless, subject to the compact internal space of the power plant, the length of the pipe is usually very short. Furthermore, the diameter of the pipe will not be small for the underwater vehicles need enough seawater for cooling and squeezing. Therefore, the pipe commonly owns the feature of short in length and large in diameter, this type of flexible pipe is difficult to design.

Dynamics of fluid-conveying pipes have been well-explored in theoretical [1-10] and experiment research [11,12]. Tan [13] investigated the vibration characteristics of pipes conveying fluid in the super-critical range using Timoshenko beam theory for the first time. FEM [14-16] is also the most popular method up to now. However, experiment methods are the most direct means to evaluate the vibration isolation effectiveness of isolators. Enrique [17] took the experimental method to investigate the two-phase flow-induced vibration in pipes, they found that dynamic pipe response increases with increasing mixture velocity and void fraction, what is more, the hydrodynamic mass parameter is proportional to mixture density. Zhou [18] and Pan [19] focused experimental research on a vibration isolation platform for momentum wheel assembly and laminated rubber bearings to isolate metro generated vibration respectively. Kaiming Bi [20] proposed properly selected viscoelastic materials and constraining layers vibrations of above-ground pipelines can be effectively mitigated. 
Double layer metal bellows (DLMB), rubber pipes (RP) and bellows coated rubber (BCR) are widely used for isolation in other engineering. However, the vibration effectiveness of the pipes has not been well explored. Especially for the sea-water pipe installed in underwater vehicles, when the sea-water pump rotates at different speeds, the excitation force and seawater pressure generated by the operation are also different. In the engineering, the working environment of the sea-water pipe is extremely complicated, and the excitation forces are varied. At the same time, in order to meet the assembly and use requirements of the product, the structure of the sea-water pipe is usually complicated, and it is difficult to accurately obtain the dynamic characteristics of the flexible pipes through theoretical calculation. To provide more comprehensive experiment evidence that testifies to the effectiveness of pipes mentioned above for the isolation of sea-water pump generated vibration, a test method was designed and carried out in the laboratory. To simulate the practical working condition, the vibration was induced by a sea-water pump and the pipes were installed between the pump and the simulation holder. In the tests, SLMB, DLMB, RP and BCR were tested respectively. In order to evaluate the isolation effectiveness of flexible pipes at different vibration levels of the sea-water pump, tests were carried out under four different rated operation speed of the sea-water pump, i.e., $1700 \mathrm{r} / \mathrm{min}, 2000 \mathrm{r} / \mathrm{min}, 2300 \mathrm{r} / \mathrm{min}$ and $2600 \mathrm{r} / \mathrm{min}$. By drawing the energy level transfer coefficients under different frequencies and rotate speeds, a universal approach to evaluating the isolation effectiveness of the sea-water pipe was provided, and the isolation effectiveness of SLMB, DLMB, RP and BCR under various levels of rpm were demonstrated.

\section{Design of the Test Specimens}

The position of the sea-water pipe in the power system is shown in Figure 1 and the sea-water pipe used in the underwater vehicle is shown in Figure 2. The sea-water pump assembly and the housing were connected by the pipe, which usually is composed by a flange, a straight line part and an elbow. In practice engineering, it is difficult to change the structure form of the flange and elbow restricted by the housing and pump structures. As a result, the straight-line part was the only part of the pipe that could be improved for better isolation effectiveness.

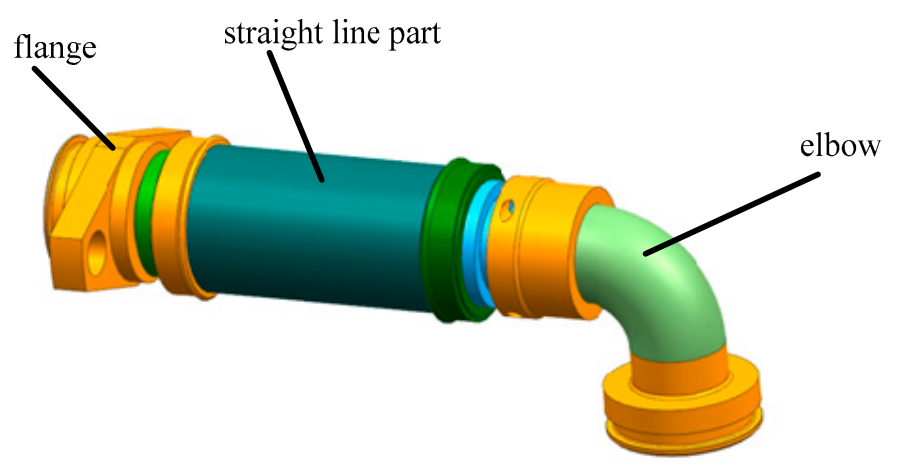

Figure 2. The structure diagram of the sea-water pipe.

To improve the flexibility of pipes and reduce the vibration transport to the housing from the pump, the following direction could be chosen: (i) reduce the pipe stiffness through adjusting the pipe structure; (ii) add high damping rubber sleeve; (iii) replace metal pipes with viscoelasticity pipes and (iv) increase pipes length.

Following the above design principles, three types of flexible pipe were designed and processing, i.e., DLMB, RP and BCR, their structures were shown in Figures 3-5. In the main view of Figure 3, the straight-line part of DLMB consists of a double metal bellows and an external metal braid. The wavy lines in the main view represent the bellows, which owns a wavelength of $3 \mathrm{~mm}$ and a thickness of $0.35 \mathrm{~mm}$. The black and white segments represent a protective steel wire braid layer. The black and red ridges each represents a layer of bellows in the partial zoom diagram. The material of the RP was 
hydrogenated nitrile rubber and the thickness was $3 \mathrm{~mm}$. Figure 5 represents the structure diagram of $\mathrm{BCR}$, which consisted of a bellows and a metal braided layer, with a rubber coating represented by a reticulated line on the outermost layer. Whose thickness was $2 \mathrm{~mm}$. The material parameters of the above three pipes were present in Table 1.

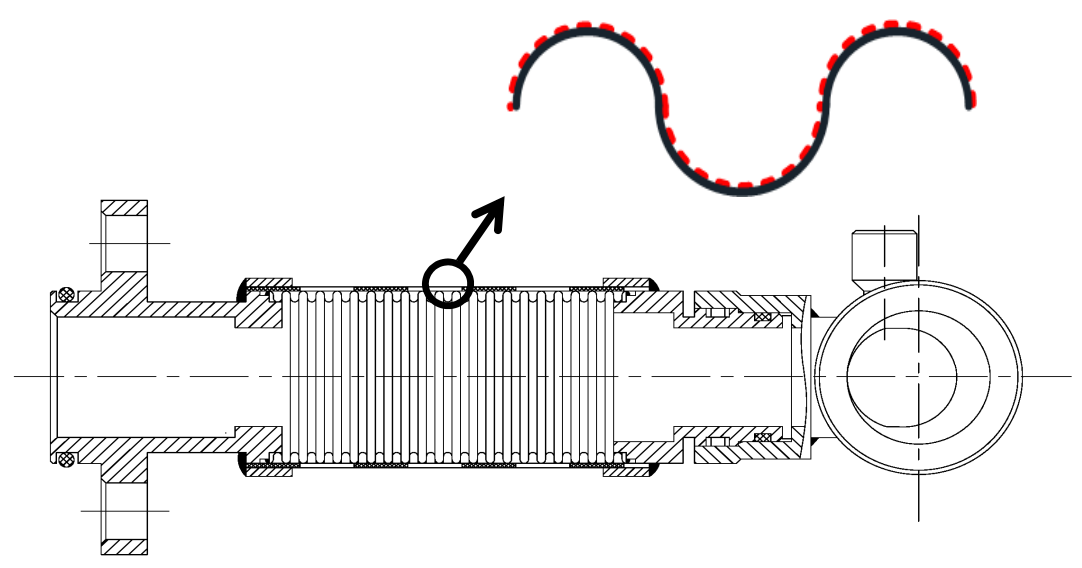

Figure 3. The structure diagram of double layer metal bellows (DLMB).

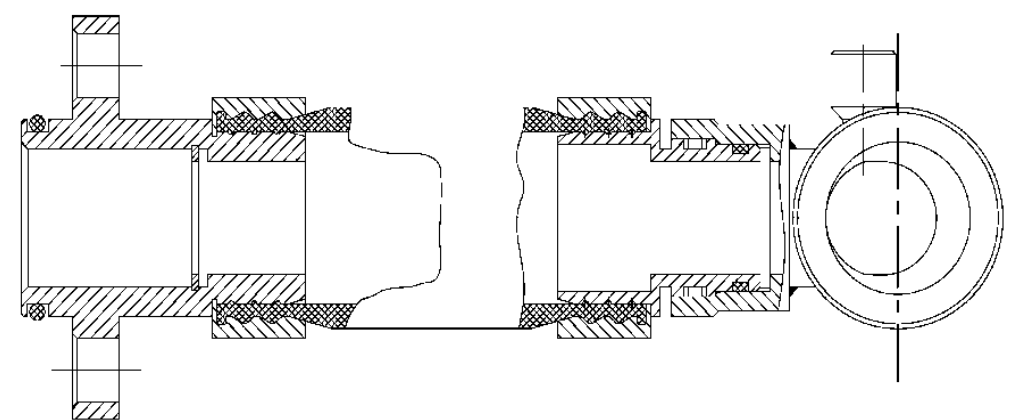

Figure 4. The structure diagram of rubber pipe (RP).

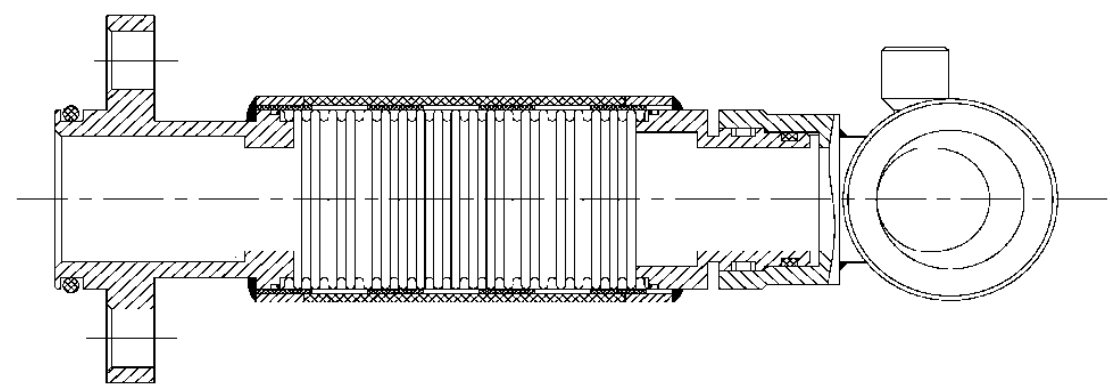

Figure 5. The structure diagram of and bellows coated rubber (BCR).

Table 1. Material parameters.

\begin{tabular}{ccc}
\hline & Rubber & Stainless Steel \\
\hline elasticity modulus (pa) & $2.8 \times 10^{8}$ & $1.93 \times 10^{11}$ \\
Poisson's ration & 0.47 & 0.30 \\
Material density $\left(\mathrm{kg} / \mathrm{m}^{3}\right)$ & 2200 & 7980 \\
Material loss factor & $5 \times 10^{-3}$ & $1 \times 10^{-4}$ \\
\hline
\end{tabular}

Compared with SLMB, DLMB owns the lower flexural stiffness under the same operation load. The vibration energy was consumed by the friction performed between the two-layer metal bellows and reached the aim of reducing the vibration transmission from the sea-water pump to the housing. 
Furthermore, there was a layer of metal mesh outside the bellows, which provided adequate axial and radial bearing capacity as well as increases the structural damping.

The material of RP was hydrogenated nitrile rubber, the high damping of the rubber could promote the mechanical impendence of the pipes, the vibration energy could be reduced by the shear deformation of the pipe.

To promote the structural damping of DLMB, a BCR was formed after a layer of rubber was covered on the outer surface of the double-layer.

\section{Test Setup}

The test setup and photo were shown in Figures 6 and 7. The sea-water pump as the vibrator of the test was riveted in the output shaft of the test bench and driven by the electrical machinery. The front and the end of the tested pipe were connected with the pump and water supply pipe respectively. Furthermore, water supply pipe was supported by the holder, which was a plate with sufficient thickness. The holder was riveted in the workbench with four bolts. The water return pipe was connected with the output of the pump. In the test, the water was transported from the water supply pipe to the pump through the tested pipes and then back to the cistern through water return pipe. There was no connection between the workbench and the electrical machinery. They were respectively fixed on the ground surface. Theoretically, in the test, there were two vibration transmission paths from the sea-water pump to the holder, one was transmitted through the sea-water pipe and the other was transmitted to the workbench through the ground. Compared with the vibration energy transferred through the sea-water pipe, the energy that the second path transfers was sufficiently low. Therefore, we could reasonably ignore the impact of this path, which would not affect the test results of the vibration isolation effectiveness of sea-water pipes.

The surface area of the sea-water pump housing was small and thick in the test. At the other end, the holder owned sufficient thickness. Therefore, in this test, we considered both the sea-water pump and the holder as a mass. In order to accurately evaluate the vibration isolation effectiveness of these pipes, we paid attention to the average vibration reduction effectiveness in multiple directions. As a result, six monitoring points were set in this model. The acceleration of each point was monitored by an acceleration transducer. Three monitoring points were set in different directions on the pump surface and represented the acceleration of the pump. Other monitoring points were on the surface of the holder in three directions and represented the acceleration after the pipe transported. The average responses value of the three directions at both ends of the pipes was utilized to characterize the vibration energy level before and after vibration isolation. The type of acceleration transducers was PCB353B04, the data acquisition system was LMS SCADAS Mobile SCM05, and the LMS.Test.Lab software was used for the acceleration test.

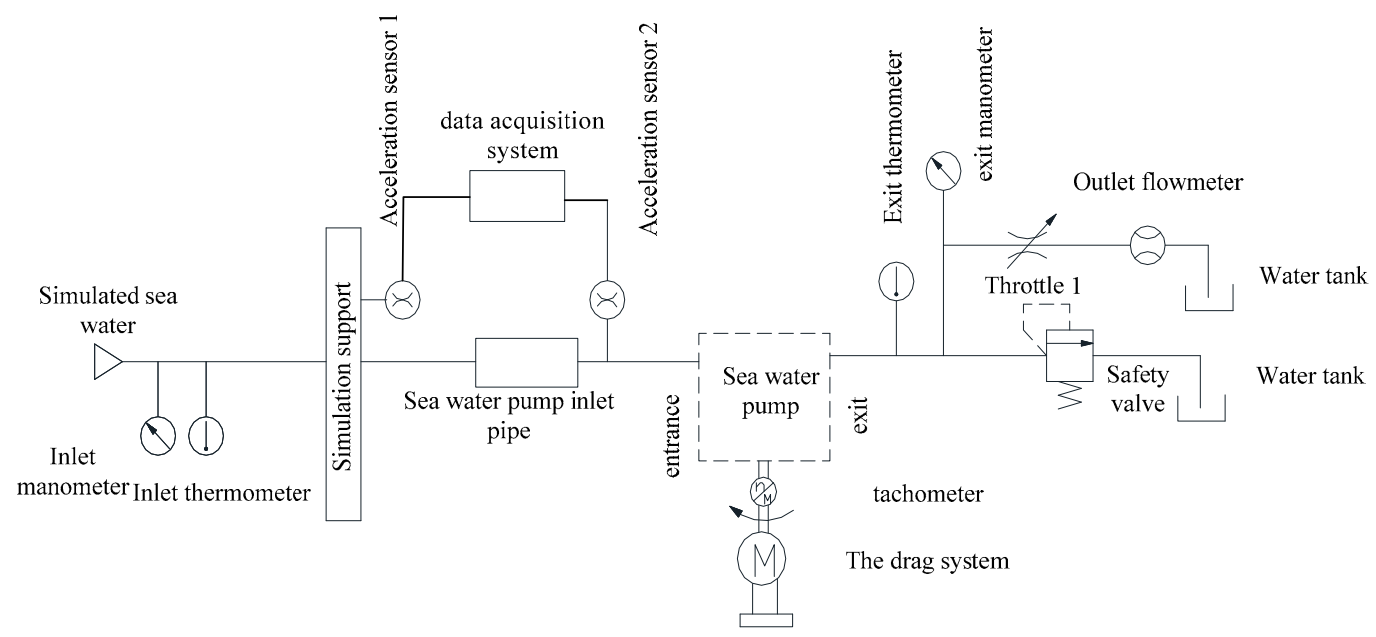

Figure 6. Schematic diagram of the test system. 


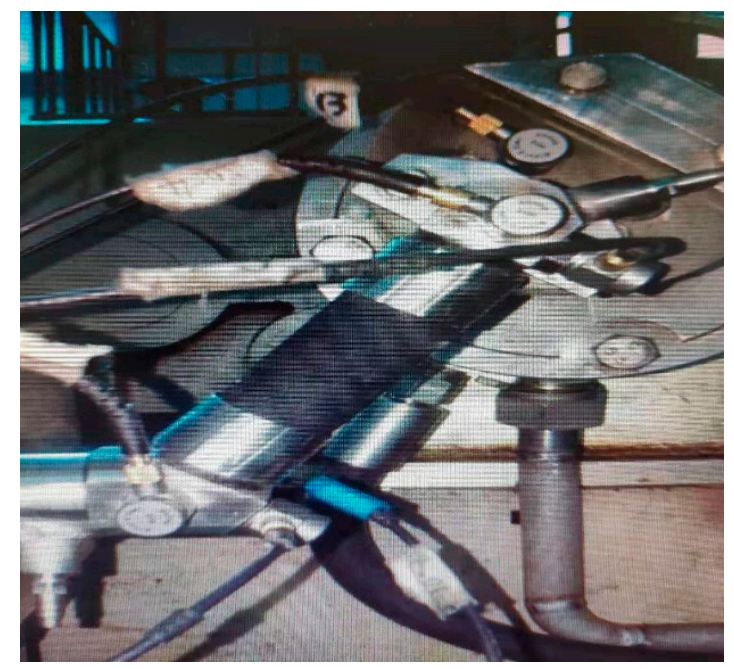

Figure 7. Testing the vibration isolation effectiveness of RP.

In the progress of the test, different vibration energy was induced at different rotate speed of the pump driven by the electrical machinery, which was controlled by the control system of the test bench. In each test condition, the sea-water pump was allowed to run stably for $3 \mathrm{~min}$. After the sea-water pump speed, flow rate and inlet and outlet pressure recorded by the pump platform were stable, time-domain vibration data acquisition was started. The signal acquisition time was $1 \mathrm{~min}$. After the data collection for all working conditions was completed, we performed FFT (Fast Fourier Transform) post-processing, and the selected window function was the Hanning window.

\section{Load Scheme}

Four stages of tests were considered, the reasons of the operation condition selection included: (i) there were many rated operating speed of underwater vehicle. (ii) The vibration energy level of the pump nonlinear increased with the increasing rotation speed and the tested pipes all owned the strongly nonlinear feature, which was obviously impacted by the vibration energy level and the frequency of the vibrator. Therefore, to accurately assess the vibration reduction effectiveness of the tested pipes in engineering, the following objectives were pursued:

- Measure the isolation effectiveness of various pipes under the $1710 \mathrm{r} / \mathrm{min}$ rotation speed of a sea-water pump.

- Measure the isolation effectiveness of various pipes under the $2000 \mathrm{r} / \mathrm{min}$ rotation speed of a sea-water pump.

- Measure the isolation effectiveness of various pipes under the $2300 \mathrm{r} / \mathrm{min}$ rotation speed of a sea-water pump.

- Measure the isolation effectiveness of various pipes under the $2600 \mathrm{r} / \mathrm{min}$ rotation speed of a sea-water pump.

\section{Isolation Effectiveness under Design Rpm}

Figure 8 showed the results of tests carried out on the four kinds of pipes under $1700 \mathrm{r} / \mathrm{min}$ to verify isolation effectiveness. The horizontal axis represented the test frequency, which was from 10 to $10,000 \mathrm{~Hz}$, the dates were recorded at $1-3$ octave(s), the curves were combined with center frequency of each 1-3 octave(s), the vertical axis represents the vibration energy level transfer coefficients $\lambda$, which was defined as

$$
\lambda=\frac{N_{2}(f)}{N_{1}(f)}
$$


where $N_{2}(f)$ was the averaged vibration energy level of transducers in all three directions, which represented the response of the holder, and $N_{1}(f)$ was the averaged vibration energy level of transducers in three directions, which represented the vibration energy of the sea-water pump. If $\lambda$ was less than unity, it meant that the vibration energy of holder was lower than the sea-water pump, the pipe owned the ability of isolation to mitigate the vibration transport from the pump to the holder, otherwise, the pipe could not be used to alleviate the vibration transport.

The main reasons for choosing to evaluate the vibration isolation effectiveness of flexible pipes in a wide frequency range were as follows:

(a) The vibration spectrum of a sea-water pump presents a typical strong line spectrum characteristic, which mainly includes the shaft frequency and its multiple frequencies, the meshing frequency of the sea-water pump gears and its multiple frequencies related to rotation at a single speed. However, in engineering practice, a sea-water pump usually owns multiple and different operating speeds at different operation time. As a result, a sea-water pump vibration response spectrum owns rich frequency information from tens of hertz to thousands of hertz.

(b) The sea-water pump is one of the main vibration sources of the underwater vehicle. The development of flexible pipes is to reduce the vibration transmission from sea-water pumps to housings and thus reduce the vibration of the underwater vehicle. For the vibration and noise reduction of underwater vehicles, the focus is on its vibration reduction effectiveness in a wide frequency band. Therefore, the selection of wide frequency bands is also due to the need for vibration and noise reduction of underwater vehicles.

(c) Different sea-water pumps have different rated speeds, flexible pipes need to have the ability to isolate the vibration of different sea-water pumps.

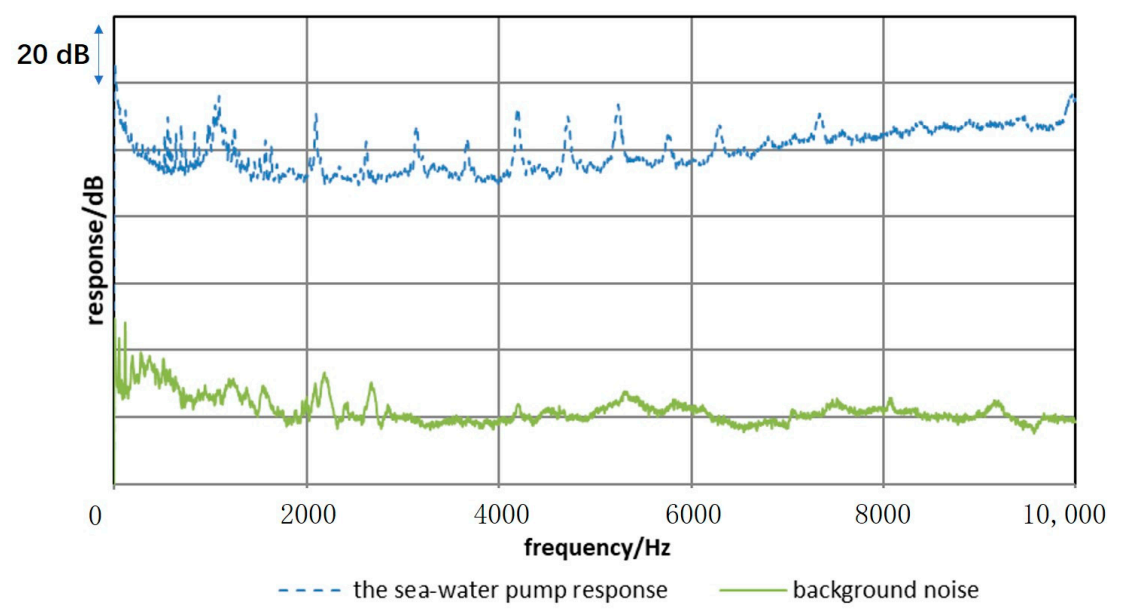

Figure 8. Signal-to-noise ratio of the sea-water pump vibration response at $1710 \mathrm{r} / \mathrm{min}$.

Figure 8 compares the vibration response of the sea-water pump at $1710 \mathrm{r} / \mathrm{min}$ with the background noise (the vibration response obtained by the sensors when the sea-water pump is not working). It can be seen from the figure that at the peak of the sea-water pump's response, the signal-to-noise ratio reached $80 \mathrm{~dB}$, and outside of the response peak frequency points, the signal-to-noise ratio at other frequencies had reached more than $40 \mathrm{~dB}$. As the rotation speed increases, the response of the sea-water pump increased. This signal-to-noise ratio was sufficient for evaluating the vibration isolation effectiveness of sea-water pipes.

As shown in Figure 9, for all the pipes, multiple peaks were observed within the test frequency range. However, compared with other pipes, SLMB obviously owned more peaks. What is more, for SLMB, $\lambda$ remained more than unity in the test frequency range except individual center frequencies, which represented that the pump vibration was magnified to the housing by SLMB in most frequency bands, the pipe offered insignificant vibration reduction. 


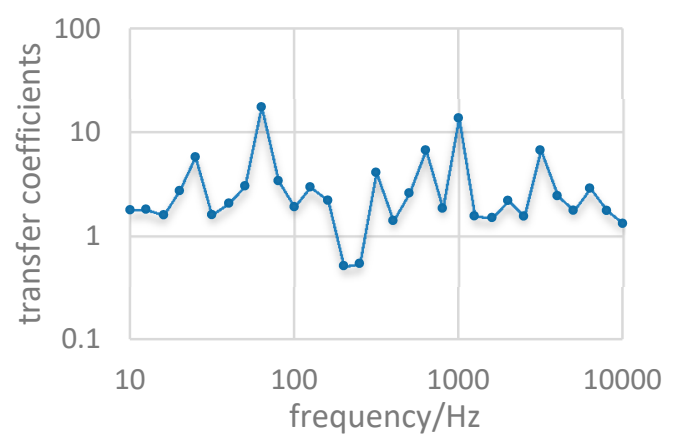

(a)

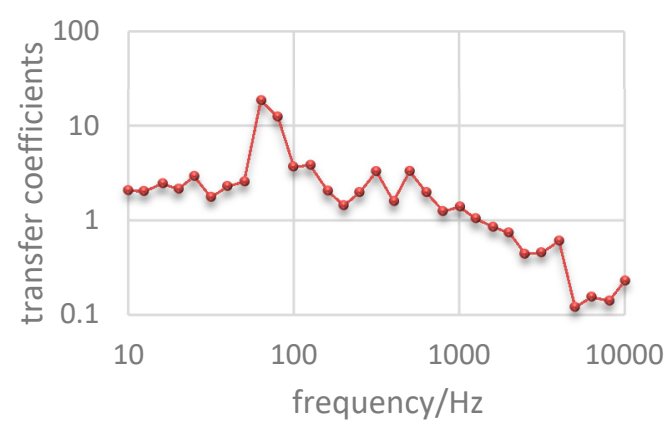

(c)

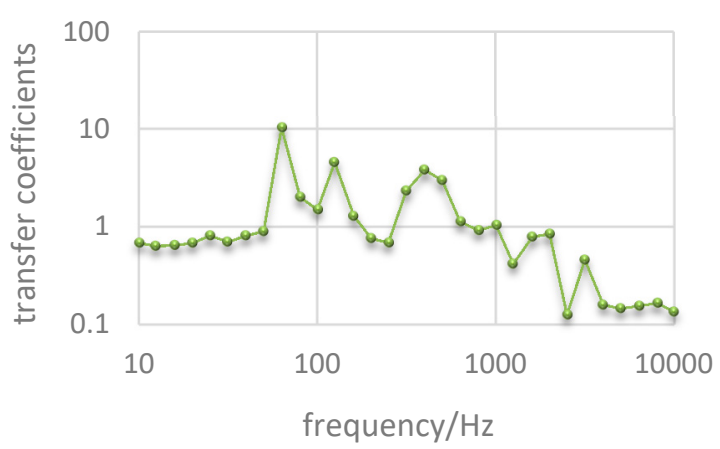

(b)

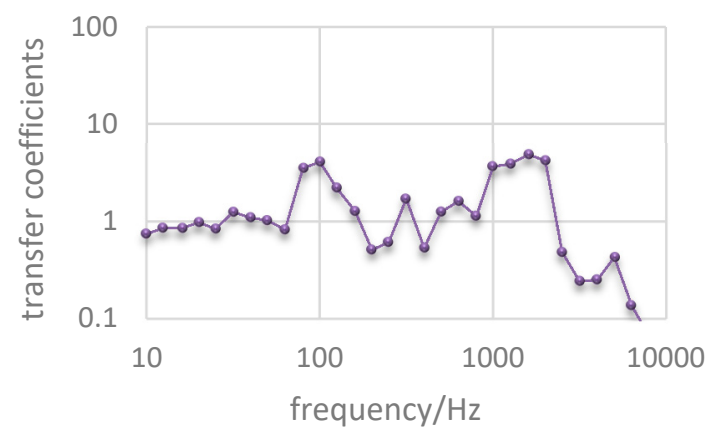

(d)

Figure 9. Test results under 1710 r/min: (a) single layer metal bellows (SLMB); (b) DLMB; (c) BCR and (d) RP.

The maximum of $\lambda$ for SLMB, DLMB and BCR within the test frequency range were all observed at the center frequency $63 \mathrm{~Hz}$. It suggested that the natural frequency of the three isolation systems located between 56.2 and $70.8 \mathrm{~Hz}$, which meant their operation stiffness were very similar. The maximum of $\lambda$ for RP occurred at the center frequency $100 \mathrm{~Hz}$, which represented that the RP owned greater stiffness in operation than other pipes. This was because the structural stiffness of RP was affected by seawater pressure, and the stiffness increased sharply as the inlet pressure of sea-water pump increased. Whereas the maximum of $\lambda$ for the RP was 4 for its high damping, this was lowest in all pipes.

It can be seen from Figure $9 \mathrm{~b}$ that the transfer coefficients for DLMB were less than unity below $50 \mathrm{~Hz}$ and above $1000 \mathrm{~Hz}$. This suggested that the pump vibration transmitted to the holder was alleviated by the pipe within the above frequency range. Moreover, the transfer coefficients kept oscillation decreasing above the nature frequency, which meant the vibration reduction effectiveness was improved with the increasing frequency.

In Figure 9c, the transfer coefficients for BCR were less than unity above $1250 \mathrm{~Hz}$, and continuously decreased with the rise of frequency. However, the vibration was magnified in other frequency bands. The transfer coefficient for the RP in Figure 9d was less than unity above $2000 \mathrm{~Hz}$ and was lower than 0.1 above $6300 \mathrm{~Hz}$, which was the lowest in all pipes.

Figure 10 showed the test results of transfer coefficient curves for the four tested pipes under $2000 \mathrm{r} / \mathrm{min}$. The transfer coefficient for SLMB was greater than unity or close to unity within the test frequency. The transfer coefficient for DLMB was less than unity above $1000 \mathrm{~Hz}$, and continued to reduce. This indicated a stable and positive vibration reduction effectiveness of the DLMB in high frequency. BCR offered good isolation effectiveness above $3150 \mathrm{~Hz}$. The transfer coefficient for RP was less than 1.2 below $63 \mathrm{~Hz}$ and lower than 0.1 above $6300 \mathrm{~Hz}$.

It can be seen from the above analysis that the test results of isolation effectiveness of different pipes were basically consistent when the speeds of the sea-water pump were $1710 \mathrm{r} / \mathrm{min}$ and $2000 \mathrm{r} / \mathrm{min}$. DLMB owned a stable vibration isolation effectiveness in the frequency band above $1000 \mathrm{~Hz}$, and the 
vibration isolation effectiveness became better as the frequency increased. BCR also applied stable vibration isolation effectiveness in the high frequency band, but due to its higher damping, its resonance region was wider, and the frequency of vibration isolation was higher than DLMB. The transmission coefficient of RP in the frequency band below $100 \mathrm{~Hz}$ was close to 1 , which indicated that the vibration of the sea-water pump was not significantly amplified by the RP, and at the same time, RP owned the lowest transfer coefficient in high frequency bands. Unfortunately, SLBM had almost no vibration isolation effectiveness in the test band.

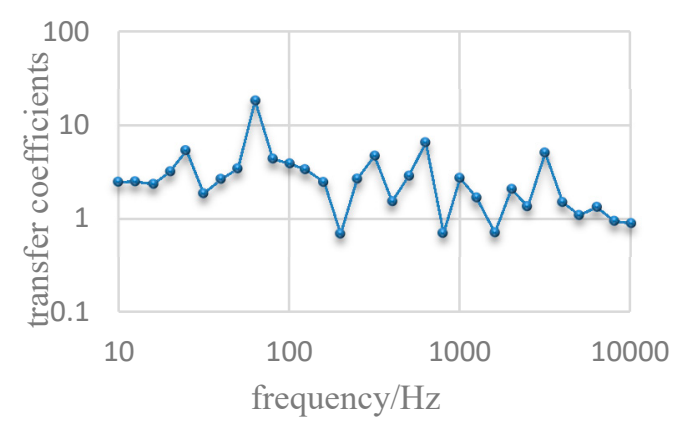

(a)

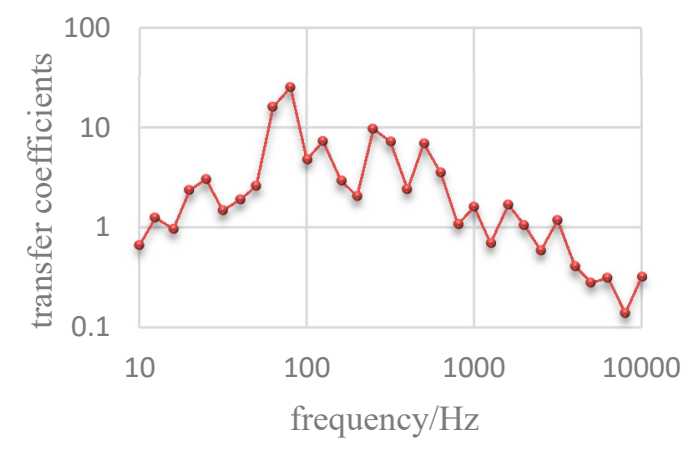

(c)

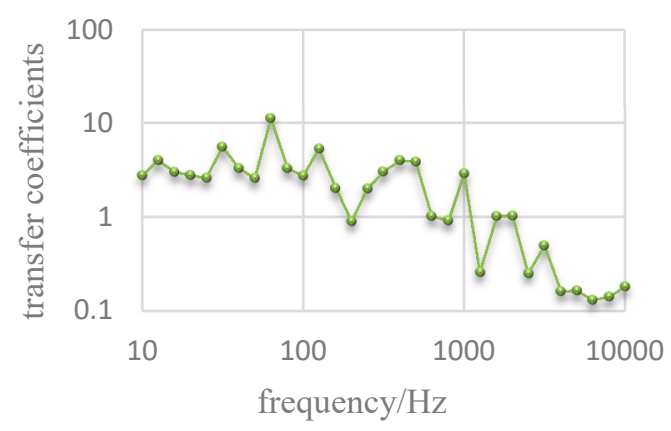

(b)

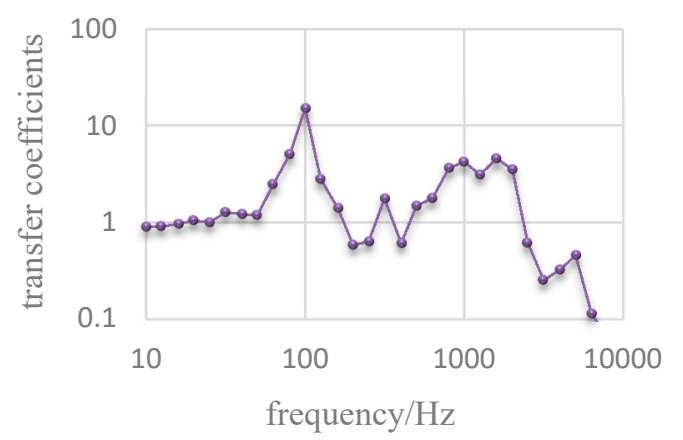

(d)

Figure 10. Test results under 2000 r/min: (a) SLMB; (b) DLMB; (c) BCR and (d) RP.

In order to find the vibration isolation effectiveness of the pipes at higher sea-water pump speeds, the transfer coefficient for the four pipes at $2300 \mathrm{r} / \mathrm{min}$ and $2600 \mathrm{r} / \mathrm{min}$ were tested. The results were shown in Figures 11 and 12. Similarly, SLMB offered insignificant isolation effectiveness within the frequency range shown in the figures. DLMB and BCR offered good vibration effectiveness in high frequency. RP always offered the most stable isolation effectiveness below nature frequency, which was the lowest in all pipes, but this phenomenon was more significant at $2600 \mathrm{r} / \mathrm{min}$.

The test results under four different conditions showed some consistency. However, subject to the influences by material nonlinearity and different excitation forces of the sea-water pump at different rotating speeds, there were also some inconsistencies. The frequency at which DLMB began to provide vibration isolation effectiveness had increased at $2300 \mathrm{r} / \mathrm{min}$ to $2600 \mathrm{r} / \mathrm{min}$ compared with the results under $1710 \mathrm{r} / \mathrm{min}$ and $2000 \mathrm{r} / \mathrm{min}$. When the speed of the sea-water pump rose from 2300 to $2600 \mathrm{r} / \mathrm{min}$, the transmission coefficient of BCR was greatly reduced in the frequency band below 200 , especially at about $80 \mathrm{~Hz}$, which was also the resonance frequency band of the vibration isolation system, the decrease was most significant. However, at the frequency range of $1000 \mathrm{~Hz}$ upwards, the peak of the curve slightly increased. Similar with the test results of the BCR, the transmission coefficient curve of RP was suddenly reduced and owned a transfer coefficient of less than unity in the low frequency band when the speed of the sea-water pump rose from 2300 to $2600 \mathrm{r} / \mathrm{min}$, but the high-frequency vibration isolation effectiveness was not as good as the results at other rotating speeds. 


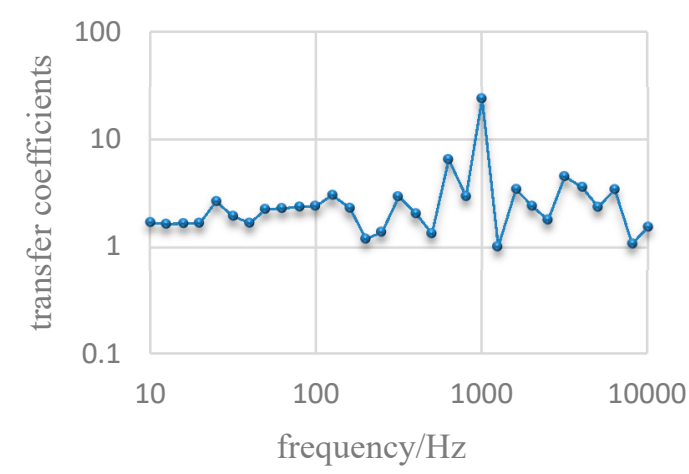

(a)

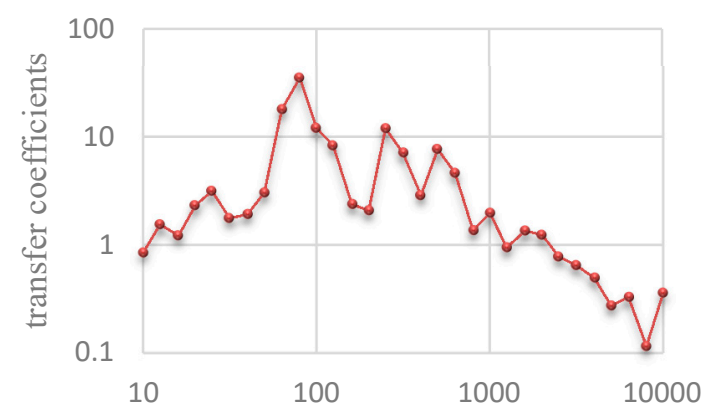

frequency $/ \mathrm{Hz}$

(c)

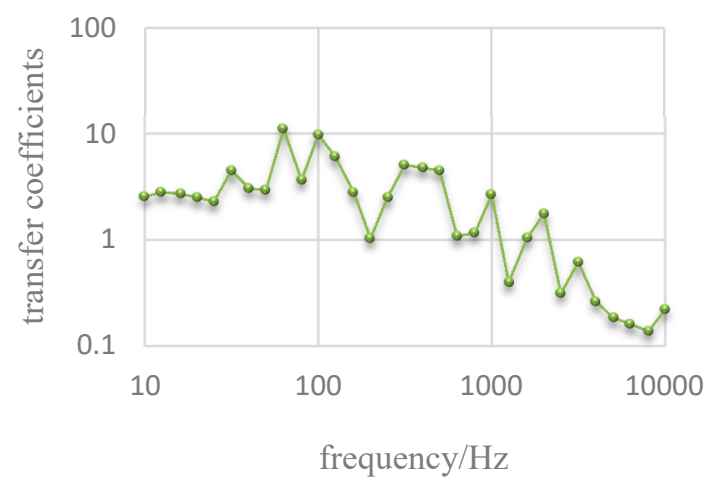

(b)

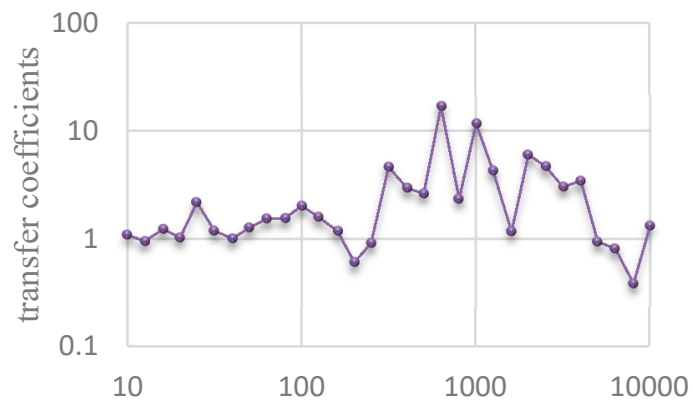

frequency $/ \mathrm{Hz}$

(d)

Figure 11. Test results under 2300 r/min: (a) SLMB; (b) DLMB; (c) BCR and (d) RP.

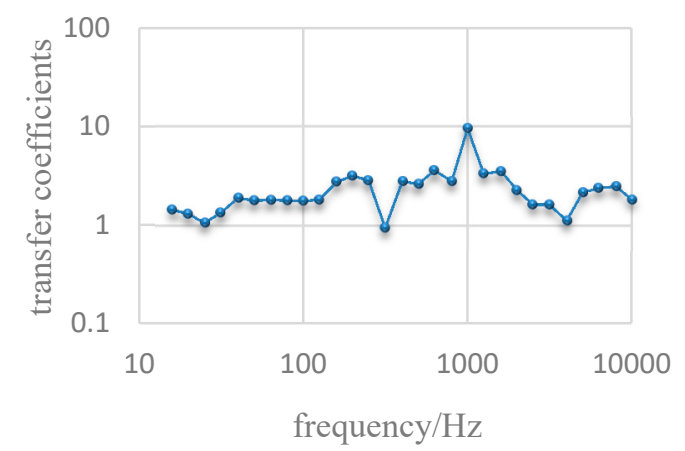

(a)

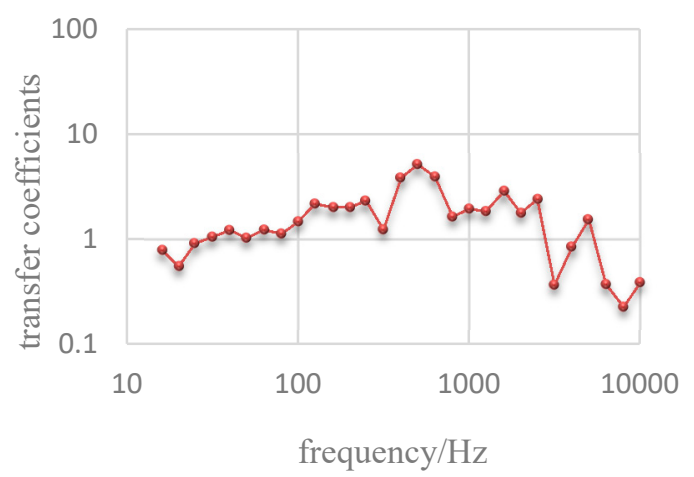

(c)

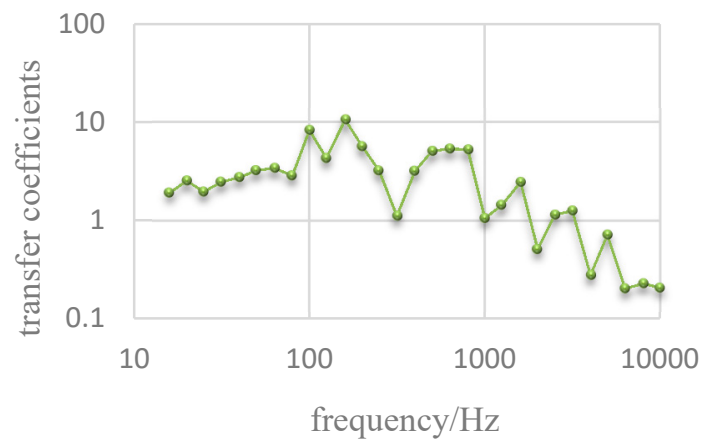

(b)

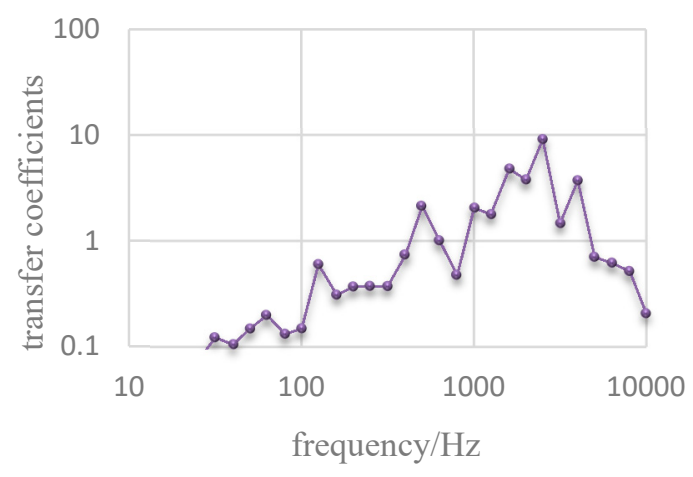

(d)

Figure 12. Test results under 2600 r/min: (a) SLMB; (b) DLMB; (c) BCR and (d) RP. 
It can be seen from the above test results and analysis that none of the flexible pipes had a good vibration damping effectiveness at all sea-water pump speeds and full frequency bands. DLMB owned a stable vibration isolation effectiveness at all speeds in high frequency bands, but had a high transmission coefficient in low frequency bands. The low-frequency vibration reduction effectiveness of BCR and RP were improved, but the high-frequency vibration isolation effectiveness was weakened. This just reflects the complexity of engineering research. In engineering practice, the multi-speed and wide-band vibration responses of sea-water pumps are inevitable, and a vibration isolator cannot take into account the full-band vibration isolation function. In order to effectively reduce the vibration transmission of seawater pumps, it is necessary to use a certain speed and a certain frequency band as input conditions for vibration isolation design under the premise of accurately analyzing the vibration frequency spectrum, so as to design vibration reduction pipes that best satisfies the engineering practice.

\section{Conclusions}

To investigate the isolation effectiveness of flexible pipes, a scaled model test was carried out. Four types of pipe, i.e., SLMB, DLMB, BCR and RP, were considered. Tests were carried out under $1700 \mathrm{r} / \mathrm{min}, 2000 \mathrm{r} / \mathrm{min}, 2300 \mathrm{r} / \mathrm{min}$ and $2600 \mathrm{r} / \mathrm{min}$. By calculation the transfer coefficient, the isolation effectiveness was established. The test results under four different conditions showed some consistency as well as some inconsistencies. Nevertheless, DLMB, BCR and RP showed their own advantages in different frequency under all conditions. The primary features are as follows:

- The transfer coefficient of SLMB was closed to or greater than unity within the tested frequency under all conditions, this suggested that the vibration transferred from the sea-water pump the holder in all frequency was increased by the pipe.

- DLMB offered the most significant isolation effectiveness of all pipes at high frequency, this indicated that the vibration of the water pump was alleviated by the pipe. However, the vibration isolation frequency of the DLMB increased as the sea-water pump speed increased.

- Similar to DLMB, BCR also owned stable vibration isolation effectiveness in the high frequency band, but its vibration isolation frequency was slightly higher than DLMB. Compared with other condition, BCR owned a sufficient low transfer coefficient at $2600 \mathrm{r} / \mathrm{min}$.

- The RP kept stabled low transfer coefficient at low frequency in all conditions, especially at $2600 \mathrm{r} / \mathrm{min}$.

Author Contributions: Contributed to Synthesis, Testing, Data Analysis, and Writing the Manuscript: Y.Y. (Yang Yang); Suggested and Supervised the Work: G.P. and S.Y.; Contributed to Revising the Language of the Manuscript: Y.Y. (Ying Yuan). All authors have read and agreed to the published version of the manuscript.

Funding: This research was funded by the Natural Science Basic Research plan in Shaanxi Province of China grant number [2019JQ-071].

Conflicts of Interest: The authors declare no conflicts of interest.

\section{References}

1. Dai, H.L.; Wang, L.; Qian, Q.; Gan, J. Vibration analysis of three-dimensional pipes conveying fluid with consideration of steady combined force by transfer matrix method. Appl. Math. Comput. 2012, 219, 2453-2464. [CrossRef]

2. Li, S.; Liu, G.; Kong, W. Vibration analysis of pipes conveying fluid by transfer matrix method. Nucl. Eng. Des. 2014, 266, 78-88. [CrossRef]

3. Liu, G.; Li, Y. Vibration analysis of liquid-filled pipelines with elastic constraints. J. Sound Vib. 2011, 330, 3166-3181. [CrossRef]

4. Bochkarev, S.; Lekomtsev, S.; Matveenko, V. Parametric investigation of the stability of coaxial cylindrical shells containing flowing fluid. Eur. J. Mech. A Solids 2014, 47, 174-181. [CrossRef]

5. Brambley, E.; Peake, N. Stability and acoustics catering in a cylindrical thin shell containing compressible mean flow. J. Fluid Mech. 2008, 602, 403-426. [CrossRef] 
6. Hu, K.; Wang, Y.; Dai, H.; Wang, L.; Qian, Q. Nonlinear and chaotic vibrations of cantilevered micro pipes conveying fluid based on modified couple stress theory. Int. J. Eng. Sci. 2016, 105, 93-107. [CrossRef]

7. Zare, A.; Eghtesad, M.; Daneshmand, F. Numerical investigation and dynamic behavior of pipes conveying fluid based on is geometric analysis. Ocean Eng. 2017, 140, 388-400. [CrossRef]

8. Zare, A.; Eghtesad, M.; Daneshmand, F. An isogeometric analysis approach to the stability of curved pipes conveying fluid. Mar. Struct. 2018, 59, 321-341. [CrossRef]

9. Zhang, W.M.; Yan, H.; Jiang, H.M.; Hu, K.M.; Peng, Z.K.; Meng, G. Dynamics of suspended micro channel resonators conveying opposite internal fluid flow: Stability, frequency shift and energy dissipation. J. Sound Vib. 2016, 368, 103-120. [CrossRef]

10. Amabili, M.; Karagiozis, K.; Païdoussis, M. Effect of geometric imperfections on non-linear stability of circular cylindrical shells conveying fluid. Int. J. Non-Linear Mech. 2009, 44, 276-289. [CrossRef]

11. Karagiozis, K.; Païdoussis, M.; Amabili, M.; Misra, A. Nonlinear stability of cylindrical shell subjected to axial flow: Theory and experiments. J. Sound Vib. 2008, 309, 637-676. [CrossRef]

12. Mekanik, A.; Païdoussis, M. Unsteady pressure in the annular flow between two concentric cylinders, one of which is oscillating: Experiment and theory. J. Fluids Struct. 2007, 23, 1029-1046. [CrossRef]

13. Tan, X.; Mao, X.Y.; Ding, H.; Chen, L.Q. Vibration around non-trivial equilibrium of a supercritical Timoshenko pipe conveying fluid. J. Sound Vib. 2018, 428, 104-118. [CrossRef]

14. Alshorbagy, A.E.; Eltaher, M.; Mahmoud, F. Free vibration characteristics of a functionally graded beam by finite element method. Appl. Math. Model. 2011, 35, 412-425. [CrossRef]

15. Park, C.H.; Lee, U.; Hong, S.C.; Kim, T.Y. Stability analysis of piping system conveying unsteady flow. Trans. Korean Soc. Mech. Eng. 1991, 15, 1512-1521.

16. Salman, H.E.; Sert, C.; Yazicioglu, Y. Computational analysis of high frequency fluid-structure interactions in constricted flow. Comput. Struct. 2013, 122, 145-154. [CrossRef]

17. Ortiz-Vidala, L.E.; Mureithib, N.W.; Rodriguez, O.M.H. Vibration response of a pipe subjected to two-phase flow: Analytical formulations and experiments. Nucl. Eng. Des. 2017, 313, 214-224. [CrossRef]

18. Zhou, W.; Li, D. Experimental research on a vibration isolation platform for momentum wheel assembly. J. Sound Vib. 2013, 332, 1157-1171. [CrossRef]

19. Pan, P.; Shen, S.; Shen, Z.; Gong, R. Experimental investigation on the effectiveness of laminated rubber bearings to isolate metro generated vibration. Measurement 2018, 122, 554-562. [CrossRef]

20. Bi, K.; Hao, H. Numerical simulation on the effectiveness of using viscoelastic materials to mitigate seismic induced vibrations of above-ground pipelines. Eng. Struct. 2016, 123, 1-14. [CrossRef] 